\title{
REASONS AND THAT-CLAUSES ${ }^{\dagger}$ \\ James Pryor \\ NYU
}

Draft 6 - 31 Mar 2007

\section{THE ONTOLOGY OF REASONS}

What are reasons? For example, if you're aware that your secretary plans to expose you, and you resign to avoid a scandal, what is your reason for resigning?

Is your reason the fact that your secretary plans to expose you? If so, what kinds of facts are eligible to be reasons? Can merely possible facts be reasons (for actual subjects)? Can merely apparent facts?

Or are reasons rather attitudes? Are your reasons for resigning your belief that your secretary plans to expose you, and your desire to avoid a scandal?

Or are reasons propositions? If so, which propositions? Only propositions that the subject believes and desires? Only propositions that are true? (On some views, those will be facts; on other views, not.)

It's hard to know how to choose between these ontologies. ${ }^{1}$

The usual view is that the ontology of reasons won't matter much to normative disciplines like epistemology and ethics. My sympathies are with this usual view. But we shouldn't underestimate the opposing evidence.

Different theorists at least talk differently about reasons.

Humeans identify a subject's reasons with her beliefs and desires. They have an easy time accounting for talk like "John resigned because he believed his secretary plans to expose him." They have to work harder to explain talk like this: "There were two good reasons for John to resign: first, his secretary plans to expose him..."

For Davidson, it's important that our reasons for acting be certain kinds of causes of our acting; so he will also tend to identify our reasons with our attitudes.

Some moral realists take the notion of objective reasons, out there in the world, as their primitive. As they see it, the fact that your glass contains petrol is a reason for you not to drink, even if you think it contains gin. ${ }^{2}$ The realists have an easy time accounting

$\dagger \quad$ Work by Jennifer Logan on that-clauses, and papers by Jeff King and Tobias Rosefeldt, stimulated this research. Thanks to Sarah Moss and Tom Kelly for their comments at the 2007 SOFIA Conference; and to the other conference participants for their feedback. Chris Barker, Ray Buchanan, David Gordon, Brett Sherman, Jeff King, Marc Moffett, and Mark Schroeder helped me with additional comments and discussion. Finally, thanks to Mark and a 2003 audience at Chapel Hill for persuading me that the notion of a reason needs to be taken seriously.

$1 \quad$ As Tom Kelly observed, it's not obvious that reasons must all be of a single ontological category. But it eases our discussion to assume they are.

2 See for example Parfit 1997, 2006; Shafer-Landau 2005; and Broome 2004. 
for talk like "One reason for you not to drink that stuff is that it's actually petrol." They have to work harder to explain talk like "The reason I drank it was I thought it was gin." In discussions of that kind of moral realism, it's sometimes said: "The facts out there in the world are objective reasons; but they can't guide your behavior until you become aware of them. That state of awareness is your subjective reason." This invites the thought that nothing can be a reason unless it has that duality: unless there's, on the one hand, some facts to provide objective support, and on the other hand, a mental attitude that represents or constitutes an awareness of those facts. If that thought is right, it ought to carry over to epistemology, too. But then it will rule out some extant theories. What is your reason for believing that you're in pain? Some theorists want to say the pain itself; there need be no further awareness that represents the pain. Similarly for beliefs: perhaps it's your first-order beliefs themselves that give you reason to believe you have them, without you needing to have any higher-order awareness of them. Perhaps these views are wrong; but they at least sound like reasonable theoretical options (see my 2005). If we think that reasons always need to be mediated by states that represent them, though, these views will be ruled out of consideration.

Like moral realists, some epistemologists also think of reasons as external facts. Unger argued that nothing can be a subject's reason unless it's true and known by the subject to be true. This prompted him to doubt whether we do believe anything for reasons. But in today's more anti-skeptical and externalist-friendly culture, the idea that external facts are reasons for belief is starting to sound like a viable theoretical option. ${ }^{3}$

So there's some basis for thinking that the ontology of reasons might matter to normative inquiries that use the notion of a reason.

It's not clear to me that epistemologists and ethicists need to use that notion. Here's an analogy. Guilt and shame are different emotional attitudes to behavior that society disapproves of. Our society employs both emotions. How do they correspond? Can we analyze guilt partly in terms of shame, or the reverse? Perhaps there's no neat analysis. Even if we discover some way that guilt and shame do map onto each other, the story might be so messy and idiosyncratic that it doesn't reveal much of theoretical use. The notions of guilt and shame might be too autonomous. Reasons, justification, and knowledge may be related in the same way. Even if we discover exactly how those notions map onto each other, the story might be so messy and idiosyncratic that it doesn't reveal much of theoretical use. If that's our actual situation, then even if reasons do turn out to be external facts, or to require a fact/representation duality, that won't straightforwardly tell us much about parallel normative notions like justification.

I suspect that is our situation. And of these normative notions, I think justification is the most fundamental.

However, whether I'm right or wrong about any of that, it should still be an interesting question to us what the right normative theory, and ontology, of reasons is. The notion of a reason is one that folk do have, and understanding it better would be philosophically useful.

3 See Unger 1975; McDowell 1994, Lectures I-II, 1995; Hyman 1999; and Silins 2004. 
This paper will be an inquiry into that ontology. We won't try to settle what upshot it should have for epistemology and ethics. And our focus will be more specific yet: we'll be considering only the merits of a single argument about the ontology of reasons.

\section{A LINGUISTIC ARGUMENT AGAINST STATISM}

Let's call the view that reasons are states like belief and desire statism. ${ }^{4}$

One consideration against statism is that ordinary language sometimes seems to identify reasons with propositions or facts. It's natural to say things like:

(1a) John's reason for resigning was that his secretary plans to expose him.

and:

(1b) John's reason for resigning was the fact that his secretary plans to expose him.

Philosophers commonly take that-clauses to be singular terms that designate propositions. ${ }^{5}$ A variant of that view says they sometimes designate propositions and other times designate facts. ${ }^{6}$ Such views suggest that (1a) should be interpreted as equating John's reason for resigning with some proposition or fact. Claim (1b) even more forcefully calls for such an interpretation. If those are the right interpretations of (1a) and (1b), it suggests that ordinary language (sometimes) understands reasons to be propositions or facts. And, although non-philosophers may say things like:

(1c) John resigned because he believed his secretary plans to expose him. I've never heard a non-philosopher say:

(1d) John's reason for resigning was his belief that his secretary plans to expose him.

So ordinary language suggests that reasons are propositions or facts.

As I've mentioned, there's also other evidence from ordinary language that supports statism. I'm not going to assess the relative strength of these different bodies of evidence. Further, we use the noun "reason" in a variety of relevant ways. We talk about "reasons there are for him to resign," "reasons he has to resign," and "his reasons for resigning." Ordinary language may be more amenable to statism for some of these than for others. I'm not going to assess that, either. My question is just: does the argument from claims like (1a) and (1b) succeed in giving any support to non-statism, about any variety of reason?

I will argue that it does not, because it interprets (1a) and (1b) wrongly.

I don't presume that non-statist views are only motivated-or are even best motivated - by appeal to linguistic arguments like the one we're considering. It's interesting in its own right what force that argument has. For me at least, it initially looks

$4 \quad$ I acquired this term from John Turri.

$5 \quad$ For a recent defense and some references, see Moffett 2005.

$6 \quad$ See Vendler 1967, Harman 2003, and Parsons 1993. 
quite attractive. And I think some of the appeal of non-statist views does draw on that attraction. Additionally, the linguistic argument relies on a widespread analysis of thatclauses whose failure will be interesting all by itself.

Consider the term "believes." It appears in a variety of forms:

(2) John believed that P.

(3) John believed this proposition [demonstrating the proposition that $\mathrm{P}$ ].

(4) John's belief that P was formed hastily.

(5) John's belief was that P.

(6) John's belief — that is, what he believed — was the proposition that P.

In some of these cases "believes" appears as a verb. I'll call the general class of such complement-taking verbs - "intends," "desires," and so on-cognitive verbs. In other cases it appears as the nominal form "belief." I'll call the corresponding general class"intention," "desire," and so on-cognitive nominals.

In some ways "reason" patterns like a cognitive nominal: compare (5) to (1a). But there's no corresponding verb form. We can say "John reasoned that P," but that means something different than we're after. We're after the notion of "reason" where John has a reason to do or think something, and that reason is, or is about, its being the case that P. I can't find any way to say that with a verbal form of "reason." So the relevant forms of (2) and (3) are missing for "reason." (I wonder whether this is an accident of etymology, or more significant.)

I doubt that our sense of "reason" has any form like (4), either. We can say "the reason that $\mathrm{P}$," but that means something other than we're concerned with.

That leaves us with (5) and (6). Compare:

(5) John's belief was that $\mathrm{P}$.

(7) John's reason was that P.

On what I'll call the orthodox semantics for that-clauses, (5) has the semantic form of:

$\left(5^{*}\right) \quad$ John's friend = Jack.

That is, (5) equates John's belief with some individual designated by "that P." Usually, this is thought to be a proposition (an abstract individual). Treating (7) on the same model, it would equate John's reason with some individual designated by "that P." This might be a proposition or a fact.

As we'll consider later, there are also uses of "John's belief" where it seems to designate a belief-state rather than a proposition believed. But that's not an available interpretation here, because the orthodox semantics doesn't let that-clauses designate states; and what (5) says might be true. So if (5), as interpreted by the orthodox semantics, is our model for analyzing (7), then the evidence seems to tell against John's reason being a state.

Compare next:

(6) John's belief - that is, what he believed — was the proposition that P.

(8a) \# John's reason was the proposition that $\mathrm{P}$.

(8b) John's reason was the fact that $\mathrm{P}$.

$7 \quad$ Perhaps we can say it using other verbs, e.g., "The fact that P motivated/led John to such-and-such." 
(8a) is infelicitous; $(8 \mathrm{~b})$ is more natural. ${ }^{8}$ On the orthodox semantics, all of these have the semantic form of:

(6*) John's friend $=$ the child Jack.

That is, (6) equates John's belief with some proposition, specifically the proposition that P. (8b) equates John's reason with some fact, specifically the fact that P. And so on.

Claims of this last type, $(8 \mathrm{~b})$, look to pose the strongest linguistic case against statism. But the difficulties I want to raise come into clearer focus with claims of type (7). Some of these difficulties also carry over to $(8 \mathrm{~b})$. But matters are murkier there, both linguistically and ontologically; and I don't have the space here to explore them. ${ }^{9}$ So our focus will be on (7).

Theorists who accept the orthodox semantics are operating with a familiar ontology of belief and other cognitive states. On that ontology, many of these states have propositional contents, and having those attitudes constitutes, or consists in, standing in certain relations to those contents. This ontology need not be threatened by the difficulties I'll be raising. If believing that $\mathrm{P}$ is standing in a relation to the proposition that P, I see no obstacle to baptizing that relation "the belief-relation." (We won't concern ourselves whether it's also a relation to any modes of presentation.) Similarly for "the wish-relation," "the fear-relation," and so on.

The orthodoxy I want to challenge goes further, and makes specific proposals about the semantics of claims like (2), (5), and so on. It says that that-clauses designate the relevant propositions, in the same way that (other) proposition-designating singular terms (hereafter, PSTs) do. So the clause "that math reduces to logic" functions semantically like one or more of:

* the name "logicism"

* the description-like phrase "the proposition that math reduces to logic"

* the complex demonstrative "this proposition" [said while demonstrating logicism]

Of course that-clauses differ syntactically from PSTs. Sometimes they are intersubstitutable:

(9a) I believed that math reduces to logic.

(9b) I believed logicism.

But compare:

(10a) I hoped that math reduces to logic.

and:

(10b) \# I hoped logicism.

(11a) \# I endorsed that math reduces to logic.

(11b) I endorsed logicism.

So the terms have different syntactic distributions. Still, it's compatible with that that they function the same semantically. General terms and adjectives also differ

$8 \quad$ Though see Dancy 2000, pp. $131 \mathrm{ff}$. for some non-factive uses of "reason."

$9 \quad$ Moltmann $2003 \mathrm{~b}$ and 2004 bear in interesting ways on this. 
syntactically, but linguists commonly take (some occurrences of) them to have the same semantic function. For instance:

(12a) John was foolish.

(12b) John was a fool.

may be semantically equivalent. Similarly, relative clauses and adjectives have different internal argument structures, but it's commonly thought that "which is empty" and "empty" are semantically equivalent (see Heim and Kratzer 1998, p. 88). In the same way, that-clauses and PSTs may also have the same semantic function.

A corollary of this will be that the verb "believes" functions the same in (9a) and (9b). In each case the verb expresses that its subject stands in the belief-relation to the proposition designated by its complement. In other words, claims of the form:

(2) John believed that P.

have the semantic form of:

(2*) John befriended Jack.

This suggests that sentences with nominal forms of "believes," like:

(4) John's belief that P was formed hastily.

may have a semantic form like:

(4*) John's friend Jack was born early.

And:

(5) John's belief was that P.

may have the semantic form of:

$\left(5^{*}\right) \quad$ John's friend = Jack.

That is the lemma that our linguistic argument against statism relies on.

Such is the semantic orthodoxy. Perhaps it sounds extremely natural: Schiffer 2003 calls it the "face-value theory." Nonetheless it is what I want now to challenge.

In $\S \S 3-4$, we'll talk about difficulties that arise for the orthodoxy's core claims, and affect its analysis even of the verbal form "believes that P." Afterwards, we'll consider difficulties that specifically concern nominal forms, as in (5) and (7).

\section{THAT-CLAUSES ARE SINGULAR TERMS?}

The claim that two expressions have the same semantic function has a weak construal and a strong construal. On the weak construal, "that P" and terms like "the proposition that P" merely have the same semantic type - perhaps $e$ or $<<e, t>, t>$. That leaves it open that their specific semantic values may differ. On the strong construal, they not only have the same semantic type, but furthermore the same semantic value.

The orthodoxy intends the strong claim, and it's the strong claim that my criticisms mainly target. So they will leave open the possibility that the weak claim is true but the strong one is false: e.g., "that P" and "the proposition that P" may both be of semantic type $e$ but their specific semantic values be different. That option may now sound bizarre; I'll explain later why it should be attractive. (My criticisms also leave it open that that-clauses have a distinct semantic type-perhaps $t$ or $<s, t>$ ).

Let's begin by reviewing the positive case that that-clauses are of the same semantic type and have the same semantic value as PSTs. The evidence here is weaker than is commonly acknowledged. 
First a point that's familiar among linguists but needs stressing for philosophers: Not every complement, or term supplying an argument, needs to be a singular term. Let's set aside clausal complements, since their analysis is what's under dispute. Perhaps this sentence has an adjectival complement:

(13a) I considered John foolish .

On the other hand, many theorists take "John foolish" in (13a) to be a "small clause," that is, a clause with a predicate but no verb. This is controversial. (The Cambridge Grammar and Partee 1987 take the contrary view that "John" and "foolish" are instead separate complements of "considered.") But if "John foolish" is a clause, then (13a) won't give us independent enough leverage on our present question.

Many linguists will at least accept these as examples whose verbs take nonnominal, non-clausal complements:

(13b) John behaved foolishly.

(13c) We treated John as a fool.

Those examples were based on Dowty 2003. Another good example is measure phrases, as in:

(14a) John weighed 150 pounds.

Here we're not saying there's any thing such that John weighed it. Weighing 150 pounds is unlike weighing an elephant. There are syntactic tests for the difference. Notice that this is good:

(14b) Was an elephant weighed by him?

whereas this is bad:

(14c) \# Was 150 pounds weighed by him?

The only way to read (14c) is with an unintended meaning, where John is measuring the weight itself, or measuring 150 pounds of something, like 150 pounds of sand. There's no reading of it where it's asking whether 150 pounds is John's weight.

There's good evidence, then, that verbs can take complements that are nonnominal. So the mere fact that that-clauses are complements won't settle what their semantic type is.

However, there are specific arguments that are thought to show that that-clauses function semantically like singular terms. One comes from propositional anaphora. Consider:

(15) John believed that P. Kristen believes that too. "That" is usually taken to be a singular term. Its antecedent here is the phrase "that P." Presumably these expressions need to have the same semantic value, for the dialogue (15) to be true. That implies that "that P" needs a singular-term semantic value, too.

Another common argument comes from inference-schemas that appear valid, and whose validity would get straightforwardly explained by the orthodox semantics. Consider:

(16a) John believed that P. Kristen believed that P. So there's something they both believed / they believed the same thing.

According to the orthodoxy, this is valid because it has the same semantic form as:

(17a) John befriended Jack. Kristen befriended Jack. So there's someone they both befriended / they befriended the same person.

Consider also: 
(16b) John believed whatever/everything Kristen said. Kristen said that P. So John believed that $\mathrm{P}$.

(17b) John befriended whoever Kristen kissed. Kristen kissed Jack. So John befriended Jack.

(16c) John believed Kristen's hypothesis. Kristen's hypothesis was that P. So John believed that $\mathrm{P}$.

(17c) John befriended Kristen's son. Kristen's son is Jack. So John befriended

Jack.

The close parallel between the (16) series and the (17) series suggests that their semantic forms, and hence the explanation of their validity, are the same. ${ }^{10}$

But these arguments are quite inconclusive. This is because there's evidence that some quantifiers, and proforms like "that," can function non-nominally.

Consider:

(18a) John tries to be friendly [adjective]. So does Kristen. So there is something they both try to be: namely, friendly.

Here it looks like the semantic values that "something" is ranging over are adjective-like values, rather than individuals. Not even abstract individuals like properties: what John and Kristen both try to be is not the property of being friendly. Consider also:

(18b) I called John friendly [adjective]. Luisa called him simpático. We called him the same thing.

Here it looks like "the same thing" functions as an adjective.

(18c) John was everything/whatever Kristen wanted him to be: friendly, foolish, and kind. (See Partee 1986, 1987.)

Here "everything" and "whatever" also range over adjective-like values.

These examples and others suggest that expressions like "something," "everything," and so on can function as non-nominal quantifiers: quantifiers whose instances take the semantic values of adjectives, general terms, and so on, rather than the semantic values of singular or referential terms. "It" and "that" can behave similarly:

10 A further argument is that the that-clause sometimes seem to occupy subject position. But the data here is complex; it doesn't straightforwardly support taking thatclauses to be singular terms. As Emonds 1972 points out, sentences like (i) "That P is John's reason" embed badly: (ii) "\# If/Although that P is John's reason..." and resist subject-aux inversion: (iii) "\# Is that P John's reason?" Koster 1978 argues that "that P" is not in subject position in (i), but rather topicalized. So (i) is akin to (iv) "As a fool was our treatment of him." We'll explore that analogy in $\S 7$, below.

11 I sketch what their semantics might look like in note 15 , below. The claim that a quantifier is non-nominal in this sense does not mean that it is "substitutional" or metalinguistic.

Many theorists have argued that quantifiers can be non-nominal. See for example Geach 1951, Sellars 1963 and 1979, Prior 1971, Williams 1981, Yablo 1996, Rayo and Yablo 2001, Künne 2005, and Rosefeldt forthcoming. Some of these theorists deny that "that P" is a syntactic unit; I (and others of them) would not say so. 
(19a) John is friendly, although he doesn't look it.

(19b) Kristen said John was friendly, and he is that. (See Ross 1969 and Mikkelsen 2004, pp. 99ff.)

Rosefeldt (forthcoming) argues that (15) and the validity of (16a)-(16c) can be accounted for without assuming that that-clauses take singular-term semantic values. The quantifiers and proforms in those examples just need to be non-nominal. And the claim that they are non-nominal has some plausibility. (Compare (16a) to (18a/b).) So at this point, I don't see a strong case that that-clauses must have the same semantic values, or even the same semantic type, as singular terms.

\section{THAT-CLAUSES AREN'T SINGULAR TERMS}

So far we've been assessing the positive evidence for the orthodox semantics. Now let's look at evidence against it.

As we saw, one can accommodate the (15)-(16) data by interpreting the quantifiers and proforms non-nominally. There's additional data that this strategy accommodates even better than the orthodox semantics. Contrast these acceptable inferences:

(20a) John hopes that P. Kristen hopes that P. So there's something they both hope.

(20b) ... So John hopes something that Kristen also hopes. to these bad ones:

(21a) John hopes that P. Kristen hopes that P. \# So there's some proposition they both hope.

(21b) ... \# So John hopes some proposition that Kristen also hopes. The orthodox analysis has no obvious account of the difference between $(20 \mathrm{a} / \mathrm{b})$ and $(21 \mathrm{a} / \mathrm{b})$. On that analysis, "something" and "some proposition" should be functioning in the same way. So, since $(21 \mathrm{a} / \mathrm{b})$ are infelicitous - you can't hope a proposition-we should expect $(20 \mathrm{a} / \mathrm{b})$ to be infelicitous too. But they're not. ${ }^{12}$

Why not? The non-nominalist Rosefeldt has an explanation: there's independent evidence that "some proposition" should always function nominally. Since "hopes" can't take a nominal complement, $(21 \mathrm{a} / \mathrm{b})$ fail. But in $(20 \mathrm{a} / \mathrm{b})$, "something" is functioning nonnominally, and so the inferences are permissible.

Similarly, this is OK:

(22a) She realized that P. I already suspected that P. So she realized something that I already suspected.

12 Some consultants judge (20a) felicitous; others will only accept “...there's something they both hope for." On some semantics, this occurrence of "for" would be semantically vacuous (see note 18, below). In any event, “...there's something they both hope for" also behaves differently than "John hopes for some proposition that Kristen also hopes for"; the differences are just more complex. 
Whereas this is bad:

(22b) She realized that P. I already knew that P. \# So she realized some

fact/proposition that I already suspected.

One doesn't usually suspect facts or propositions. (What should one suspect them of?) So (22b) can't felicitously be read in the intended way. On the orthodox analysis, (22a) should then fail too. But it doesn't. So here again it's plausible that "something" is functioning differently than "some fact" or "some proposition."

Here is another problem (see Bach 1997, McKinsey 1999, and Moltmann 2003a). As we saw before, that-clauses and PSTs are sometimes inter-substitutable:

(9a) I believed that math reduces to logic.

(9b) I believed logicism.

But some verbs (like "hopes") accept only the clausal complements; and others (like "endorses") accept only the singular term complements. Those facts may have purely syntactic explanations. What's awkward for the orthodox analysis are other sorts of substitution failures, where the verbs accept both kinds of complement, but substitutions as in $(9 \mathrm{a} / \mathrm{b})$ can affect truth-value. For example, these:

(23a) John forgot that $P$.

(23b) John forgot the proposition that P.

don't seem to mean the same thing. In this case, there may be other singular terms that are intersubstitutable with the that-clause. Perhaps the following can mean the same as (23a):

(23c) John forgot the fact that $P$.

But there are many cognitive verbs where no singular term seems to be substitutable salva veritate for "that P":

(24a) John saw that P.

(24b) John saw the proposition that P.

(24c) John saw the fact that $P$.

Neither (24b) nor (24c) nor anything else of that sort seems to mean the same as (24a). So too with other perceptual verbs, and with "suspects," "expects," "demands," "requests," "desires," "fears," and so on:

(25a) John expects that math reduces to logic.

(25b) John expects logicism.

(26a) John feared that math reduces to logic.

(26b) John feared logicism.

King 2002 offers a response to this problem that orthodox theorists may want to make use of. ${ }^{13} \mathrm{He}$ argues that verbs like "sees," "expects," and so on are ambiguous, and that what meaning they take depends on the syntax of their complement. When the complement is a that-clause, "sees" gets the "observed-to-be-true" meaning; when it's a

13 King does not himself officially embrace the orthodoxy; he is sympathetic to the revised semantics I go on to propose. However, he's skeptical that different semantic values for "logicism" and "that math reduces to logic" explain the phenomena we're discussing here. 
singular term, even a singular term designating a proposition, it gets the "spies" meaning. That is why the substitutions $(24 \mathrm{a} / \mathrm{b})$ and $(24 \mathrm{a} / \mathrm{c})$ don't preserve truth-value.

As evidence for this proposal, King notes that sentences like:

(27a) \# John expects that set theory is consistent, and Kristen reporters/logicism. cannot be felicitously read to mean:

(27b) John expects that set theory is consistent, and Kristen expects reporters/logicism [to arrive].

The verb "expects" appears only once in (27a), which is evidence that it will only (felicitously) contribute a single interpretation. This assumption - that an expression with one overt appearance will only felicitously contribute a single interpretation - is the basis of many tests for ambiguity. But we see that (27a) is infelicitous. This suggest that "expects" needs to have two interpretations to get the meanings it has in (27b), and in $(25 \mathrm{a} / \mathrm{b})$.

I think King is right that substitutions with different syntax often affect the meaning of verbs like "sees" and "expects." But I'm not persuaded this will be enough to rescue the orthodox analysis. I have several reservations.

First, King's account naturally predicts that "sees" should take its "spies" meaning when conjoined with "something." However, we can say "John saw something" to mean that there's some proposition P such that John saw that P. What is going on here? Why should "sees" sometimes take its "spies" meaning when conjoined with "something," and other times take its "observed-to-be-true" meaning? The same is true for "nothing" and "everything." King acknowledges that these quantifiers behave specially. He points out that they do so in a variety of other contexts, too: they are systematically able to occur where other NPs, like "some proposition," cannot. But he has no explanation of why.

Rosefeldt has a principled explanation: the relevant uses of "something" are nonnominal — and thus, so too are the that-clauses whose semantic values they range over. This abandons the orthodox analysis of that-clauses.

Second, consider:

(28) John fears reporters, and that he will be judged a fool.

Here it seems perfectly acceptable for a single occurrence of "fears" to mean both "is scared of" and "anxiously believes-may-be-true." If we retain the assumption that one overt appearance means only a single interpretation, then "fears" needs to be interpreted in a way that includes both of those meanings. That makes it less plausible that the difference between:

(26a) John feared that math reduces to logic.

(26b) John feared logicism.

comes from there being two different interpretations of "fears."

Admittedly, the following:

(26c) ? John feared logicism, and that math reduces to logic.

is awkward. And I agree with King that (27a) is infelicitous. But as I'll explain, the orthodox analysis is in trouble if there are any examples of this sort that are acceptable. That is a heavy burden. Here are some possibilities:

(29a) John understood logicism, and that it was true.

(29b) John explained logicism, and that it was true. 
The relations John needs to stand in to logicism for the first conjunct to hold are different than the relations he needs to stand in to it for the second conjunct to hold. Yet the verbs in each case appear only once. So we can assume they contribute only a single interpretation; that can't be where the difference in truth-conditions comes from. It needs to come from different contributions by the complements. Yet they differ only in that the first is a PST and the second a that-clause expressing (nearly) the same proposition. ${ }^{14} \mathrm{I}$ don't see any easy, satisfying way to reconcile the truth-conditional differences exhibited between the conjuncts in (29a) and (29b) with the orthodox view that the complements should be making (nearly) the same contribution.

Consider also:

(29c) John understood logicism, and Kristen that set theory is consistent. This is less natural than (29a), but it still sounds alright to some consultants. I expect it to mean the same as:

(29d) John understood logicism, and Kristen understood that set theory is consistent.

(though I'm not completely certain it does). If it does mean the same as (29d), then there's a difference between the relations John and Kristen need to stand in to their respective propositions: Kristen needs to know that her proposition (let's call it "Consistency") is true. Compare:

(29e) Kristen understood Consistency, and John that math reduces to logic. Here it's John who needs to know that his proposition is true. But if "understood" is only contributing a single interpretation to each sentence, and "logicism" and "that math reduces to logic" contribute the same semantic value, and likewise for "Consistency" and "that set theory is consistent," then where does the difference in truth-conditions between $(29 \mathrm{c})$ and $(29 \mathrm{e})$ come from?

I think we should give up the orthodox view that that-clauses make the same semantic contributions as corresponding PSTs, like "logicism" and "Consistency."

A parallel may help. It's natural to think of calling as a relation between an agent, a patient, and something the patient is called. In an example like:

(30a) John called Kristen friendly.

we may at first say that the final argument is the property of being friendly. But now suppose that John has strange metaphysical views. He thinks that Oscar the Grouch is the number five, and that Kristen is a property. And he says so. So:

(30b) John called Oscar the number five.

(30c) John called Kristen the property of being friendly / friendliness. (30c) reports a very different attribution from (30a). The difference between them can't be assigned to a shift in the meaning of "call," for we can just as easily say:

(30d) John called Kristen friendliness, and me friendly.

14 I say nearly the same, because on some views the proposition that $\mathrm{P}$ is true will be distinct from the proposition $\mathrm{P}$ itself. But that does not provide any promising escape hatch here. With more set-up, it's possible to give example that don't use truth. More importantly, even in $(29 \mathrm{a} / \mathrm{b})$, the relations John needs to stand in to logicism for the first conjunct to hold are different than the relations he needs to stand in to the proposition that logicism is true, for the second conjunct to hold. 
Examples like (30d) invite us to revise the claim that calling is a relation to properties. We need to distinguish the relation exemplified in (30a), and the final conjunct of (30d), from the relation exemplified in (30c) and the other conjunct of (30d). If "friendliness" and "friendly" are complements of "called" (as The Cambridge Grammar, though not small-clause theorists, will say), then the different semantic roles they're playing in (30d) require them to be making different semantic contributions.

What I'm urging is a similar revision for propositions. (29a)-(29e) attest that there are different ways to be related to a proposition, which can be included in a single interpretation of the verb. There may be various theoretical options to accommodate that. But one simple, easy option is to abandon the orthodox analysis - at least its strong claim that "logicism" and "that math reduces to logic" have the same semantic value. Instead, let them take different semantic values. Then the extension of a verb can include the one semantic value, or the other, or both. That immediately delivers the truth-conditional differences we need between the conjuncts in (29a)-(29e).

What might the different semantic values be? Nothing exotic is yet mandated. For all I've said so far, we might just let the semantic value of "logicism" be a pair: $<0$, the proposition that math reduces to logic $>$ and the semantic value of "that math reduces to logic" be the different pair: $<1$, the proposition that math reduces to logic $>.{ }^{15}$

15 Compare Kaplan 1989's discussion of "Plexy" at footnote 23. The issues we're discussing are related.

At this point I can briefly sketch a truth-theory for non-nominal quantifiers. See Rosefeldt forthcoming for more details (and a slightly different approach); and compare Heim and Kratzer 1998, pp. 212-13. We need to antecedently settle on a way to distinguish the semantic values of singular terms from the semantic values of other terms. I'll confine myself to an extensional language, with some predicative quantifiers. Let the semantic value of "Kristen" be $<0$, Kristen $>$. We associate the predicate "friendly" with an extension that includes semantic values like that. For present purposes, let's identify that extension with the property friendliness. We want though to distinguish between the semantic values of "friendly" and "friendliness." As with other singular terms, let's give "friendliness" the semantic value $<0$, friendliness $>$; and let's give "friendly" the semantic value $<2$, friendliness $>$. Then a sentence like "Kristen is friendly" will be true because the semantic value of "friendly" is $<2, \mathrm{~F}>$, where $\mathrm{F}$ is the extension friendliness, and $<$ the semantic value of "Kristen" $>\in$ F. "John called Kristen friendly" will be true iff the semantic value of "called" is $<2, \mathrm{G}>$ for an extension $\mathrm{G}$, and $<$ the semantic value of "John", the semantic value of "Kristen", the semantic value of "friendly" $>\in$ G. (Notice that truth-condition will differ from the truth-condition of "John called Kristen friendliness.") A nominally quantified sentence, "(Someone $x)(x$ called Kristen friendly)" will be true (relative to an assignment A) iff there's any assignment $A^{*}$ of semantic values to variables (differing from $A$ at most wrt " $x$ ") such that $<A^{*}(" x$ "), the semantic value of "Kristen", the semantic value of "friendly" $>\in$ G. In this case, that will be true when $\mathrm{A}^{*}$ assigns " $x$ " the semantic value $<0$, John $>$. A predicatively quantified sentence, "(Something $F$ ) (John called Kristen $F$ )" will be true (relative to an assignment A) iff there's any assignment $A^{*}$ (differing from $A$ at most wrt " $F$ ") such that $<$ the semantic value of "John", the semantic value of "Kristen", $\mathrm{A} *($ " $F$ ") $>\in \mathrm{G}$. In this case, 
Does this mean that "logicism" and "that math reduces to logic" designate or refer to different things? Not necessarily. We needn't identify the folk semantic notion of "reference" with our more theoretical notion of semantic value. Consider that a Montagovian, who says that names have as semantic values sets of extensions, needn't say that that's what a name refers to. He can say a name refers to its bearer (who will be the unique member of the intersection of all those extensions). So, too, in the present case we're free to say that what that-clauses and PSTs designate or refer to are the propositions that come second in their semantic values. We just need the semantic values themselves to be distinct, so that we can distinguish a verb's having the one in its extension from its having the other.

Now my own preference is to give "logicism" and "that math reduces to logic" more radically different semantic values, which reflect their different semantic functions. I'd also like to abandon the view that these expressions have the same semantic type. But I can't claim to have shown that any such radical changes are necessary. The considerations we've reviewed only require that there be some difference in the expressions' semantic values.

If examples like (29a)-(29e) pressure us to make such a move anywhere, we'll need to make it across the board. Hence even sentences like these will need to be analyzed differently:

(9a) I believed that math reduces to logic.

(9b) I believed logicism.

What needs to be in the extension of "believes" for (9a) to be true will be different from what needs to be there for $(9 b)$ to be true. However, though the semantic analyses differ in that way, we may choose to say that "believes" belongs to a class of cognitive verbs whose extensions include the one semantic value iff they include the other. This would make (9a) and (9b) "semantically equivalent," in the sense that the same extra-linguistic facts make them true.

Where does this leave us? If that-clauses don't take singular-term semantic values with cognitive verbs, then probably they don't take them with cognitive nominals either. The orthodox analysis claimed that these:

(5) John's belief was that P.

(7) John's reason was that P.

have the semantic form of:

$\left(5^{*}\right) \quad$ John's friend $=$ Jack.

But now we've argued that the complement in (5) and (7) doesn't have the same semantic value as any singular term. Whereas "John's belief" and "John's reason" clearly are singular terms. So if (5) and (7) really did have the semantic form of $\left(5^{*}\right)$, they'd presumably be false. We can conclude that (5) and (7) don't have that semantic form; their copulas aren't the "is" of equality.

In which case, (7) isn't directly telling us anything about the ontology of reasons.

that will be true when $A^{*}$ assigns " $F$ " the semantic value $<2$, friendliness $>$. All of this will of course be more complicated for an intensional language, or for different choices of semantic values. But this captures the basic idea. 
Our discussion has been brief, and I cannot claim to have refuted the orthodox analysis. So I propose for the remainder of our discussion to grant that analysis. Even if that-clauses $d o$ function semantically like PSTs, I'll argue that there are additional reasons, specific to cognitive nominals, for thinking that (5) and (7) don't have the semantic form of $\left(5^{*}\right)$.

\section{STATE/CONTENT “AMBIGUITIES”}

Sometimes cognitive nominals seem to designate a state or attitude, and other times the state's content. Thus we can say that Oscar's desire (the state) grew stronger every year, or that his desire (what he desires) is unattainable. Commonly it's thought that these nominals are just ambiguous (polysemous), in the way that "Oscar's purchase" can designate an event that lasted three hours, or a piece of furniture that doesn't fit through the door. However, the data with cognitive nominals is interestingly complex, and I'm going to argue that a simple ambiguity account is inadequate. They're either not ambiguous, or they're not ambiguous everywhere they're commonly alleged to be.

This will bear on the claim I'm opposing, that the copulas in (5) and (7) are the "is" of equality.

Suppose Oscar is grouchy, but secretly desires to be well-liked, and in fact is (though he won't admit it) already well-liked. Then we can say:

(31a) Oscar's desire is that he be well-liked.

(31b) Oscar's desire is secret.

On the equative analysis of (31a), "that he be well-liked" designates a proposition, and "Oscar's desire" has its "what he desires" reading. Whereas in (31b), "Oscar's desire" needs to have its state reading: it's not a secret that Oscar is well-liked. All that's secret is that he desires that to be true.

Now generally, when examples exploit an ambiguity in the way (31a) and (31b) are claimed to, we won't be able to felicitously conjoin the predicates. Thus we can't say:

(32a) \# Oscar's purchase, which lasted three hours, doesn't fit through the door. Neither can we say:

(32b) \# Oscar's three-hour-long purchase doesn't fit through the door. But there doesn't seem to be any problem with:

(33a) Oscar's desire, which is secret, is that he be well-liked. ${ }^{16}$

Or:

(33b) Oscar's secret desire is that he be well-liked.

16 Another example that sounds acceptable is: "After Chase Bank lowered its interest rates, it burned down and was rebuilt across the street." My view is that felicitous sentences like this are not ambiguous. Instead, it attributes several properties to a single bank institution (some of them properties it has in virtue of what happens to its building). Similar diagnoses can be given for some other examples. Contrast "\# Chase Bank, the three-story structure on 4th St, just fired half its employees." That's bad in the way (32a) is: it really does exhibit a (failed) attempt to give "Chase Bank" two interpretations. 
The equative analysis would lead us to expect that $(33 \mathrm{a} / \mathrm{b})$ are claiming there's something which is both identical to the proposition that Oscar be well-liked, and is Oscar's desire, and is secret. But there's no such thing. The proposition that Oscar (in fact) desires is no secret. It's only his state of desiring it which is secret.

I think a better account of what's going on here is that "Oscar's desire" always refers to Oscar's state - at least in examples of the sort we're considering — and "is that P" should be interpreted as meaning, not "= the proposition that $\mathrm{P}$," but rather as something like "has the content: P.",17

We can see this phenomenon with cognitive nominals that take non-clausal complements, too. Google turns up:

Then she began to pray very specifically, saying "Lord I would really love to be able to combine my talent in PR and marketing with my passion, which is you."

I don't think the woman being discussed wants to combine her talent with God. Rather, she wants to combine her talent with her standing passionate attitude. So "my passion" designates an attitude of hers, rather than an object of passion. Yet she goes on to say that her passion "is you," that is, is God. Presumably she doesn't identify God with any of her own attitudes. Hence, when she says that her passion "is you," we have to understand that as meaning "has as its content: you," not as meaning "= you."

If this proposal is right, then it should guide our analysis of:

(5) John's belief was that P.

(7) John's reason was that $P$.

If "was that $\mathrm{P}$ " in these examples doesn't mean "= the proposition that $\mathrm{P}$," then again (7) isn't directly telling us anything about the ontology of reasons.

\section{PREDICATIONAL COPULAS?}

When I presented this material at the SOFIA Conference, I formulated the proposal of $\S 5$ as: the copula in (5) and (7) is predicational rather than the "is" of equality. However, as Sarah Moss argued in her reply, examples like (5) and (7) fare poorly against recognized tests for having a predicational copula.

For example, the following is clearly predicational:

(31b) Oscar's desire is secret.

And the following are clearly not:

(34) He/This is Oscar. [demonstrating him]

(35) They are Oscar and Grover and Kermit and Ernie. [demonstrating them] Notice the differences:

(36a) I considered Oscar's desire secret. [see Rothstein 1995]

17 Considerations like these may help us with sentences like (8b). Consider "The knowledge that Oscar lacks is the fact that he's already well-liked." What Oscar lacks is presumably a knowledge-state, not a fact. Hence "is the fact that he's already well-liked" should be understood not to mean "= the fact that $\mathrm{P}$," but rather to be telling us what fact it is that Oscar's knowledge-state is of. I think a parallel diagnosis of ( $8 \mathrm{~b})$ is also viable. 
(36b) \# I considered him Oscar.

(37a) Most of Oscar's desires are secret. [see Iatridou and Varlokosta 1998]

(37b) \# Most of them are Oscar and Grover and Kermit.

Sentences like "Oscar's desire is that he be well-liked" seem to pattern more in the nonpredicational b-way:

(38) \# I considered Oscar's desire that he be well-liked.

This can't felicitously be read in the intended way, to mean that you considered Oscar's desire to be a desire that he be well-liked. Also:

(39) ? Most of Oscar's desires are that he be well-liked, that he accumulate lots of trash, and that he be grouchy.

These data suggest that the copula in "Oscar's desire is that P" is not predicational, after all.

But now consider:

(40a) Kristen's annoyance is with John.

This also seems to fail tests for being predicational:

way]

(40b) \# I considered Kristen's annoyance with John. [can't be read in intended

(40c) ? Most of Kristen's annoyance is with John and with Oscar.

How then should (40a) be understood? Some semanticists would construe the occurrence of "with" in it to be semantically vacuous, so that "with John" has the same semantic value as "John."18 But (40a) is not plausibly read as equating Kristen's annoyance with John. "Kristen's annoyance" can't standardly be used in that way. We can't standardly say:

(40d) ? John is Kristen's annoyance.

If, on the other hand, "with John" has some other kind of semantic value - perhaps an intensional transitive content? - it'd still be implausible that (40a) equates Kristen's annoyance with that.

We can express equations in the neighborhood:

(41) I met the man Kristen was annoyed with. He was John.

But they behave differently than (40a):

(42a) Kristen's annoyance, which had been building for an hour, was with John.

(42b) \# He / The man Kristen was annoyed with, which had been building for an hour, was John.

So what's going on? If examples like (40a) aren't predicational, and they're not plausibly equations, either, what are they?

\section{SPECIFICATIONAL COPULAS}

Higgins 1973 proposed four uses of the copula: the two philosophers are familiar with (predicational and what linguists call equative), as well as a "specificational" use and an "identificational" use. Let's set the identificational uses aside; they can plausibly be analyzed as instances of some of the others.

18 See Heim and Kratzer 1998, pp. 61-4. 
Specificational claims are exemplified by the most natural reading of:

(43a) What we saw in the park was a man and a woman.

to mean that we saw a man in the park and we saw a woman in the park. That sentence also has a more unusual predicational reading, that predicates being both male and female of some one individual we saw in the park. An equative claim would instead require a plural copula, as in:

(43b) We saw some people in the park. They were a man and a woman.

Some linguists regard specificational claims as a kind of equative claim (e.g., Heycock and Kroch 1998, 1999). But others argue that specificational and equative copulas behave differently. Mikkelsen 2004 presents the following tests. These are predicational:

(44a) The woman John was seeing was pretty, wasn't she [\#it]?

(44b) The woman John was seeing, she [\#it] was pretty. These are equative:

(45a) You met the woman John was seeing. She was Kristen, wasn't she [\#it]?

(45b) The woman John was seeing, she was Kristen. These are specificational:

(46a) The woman John was seeing was Kristen, wasn't it?

(46b) The woman John was seeing, that was Kristen.

If we do admit a distinct specificational use of the copula, how should we semantically analyze it? This is disputed. Schlenker 2003 and Romero 2005 argue that the pre-copular material is a concealed question. On such an account, (46a) has the semantic form of:

$\left(46 a^{*}\right)$ Who was the woman John was seeing? Kristen [was the woman John was seeing].

Mikkelsen joins a different tradition, that analyzes specificational claims as inverted predicational claims: that is, the predicative element occurs before the copula, and its argument occurs after the copula (see also Williams 1983, Partee 1986, and Moro 1997). On such accounts, (46a) instead has a semantic form like:

$\left(46 \mathrm{a}^{\prime}\right) \lambda x$ ( $x$ uniquely is a woman John was seeing) (Kristen)

Higgins gives examples like these of the difference between predicational and specificational claims:

(47a) How John appears is important to him.

[predicates "being important to John" of the way John appears]

(47b) How John appears is important to himself.

[specifies the way John appears: namely, as self-important]

(47c) Nixon's peace plan is a bomb.

[understood to predicate "bombing," that is, failing, of Nixon's plan]

(47d) Nixon's peace plan is a bomb.

[understood to specify the content of Nixon's plan: namely, to use a bomb] These examples are suggestively close to the alleged state/content ambiguity we were discussing in $\S 5$. Let's see if we can treat the kinds of cases we've been discussing with this apparatus.

We'll confine ourselves to cases where the pre-copular element is a cognitive nominal; and we'll begin with cases where the nominal's argument is a (canonical) 
singular term. Suppose that John chose Kristen, and consider the nominal "John's choice.” By Mikkelsen's tests, this looks to be predicational:

(48a) John's choice was blonde, wasn't she [\#it]?

This looks to be equative:

(48b) You met the woman John chose. She was Kristen, wasn't she [\#it]?

These 1/ook to be specificational:

(48c) John's choice was Kristen, wasn't it [?she]?

(48d) John's choice, which was coerced, was Kristen, wasn't it [\#she]?

Notice how (48d) comes out if we try to interpret it as equative. It would have to mean there is something which is John's choice, which was coerced, and which is equal to Kristen. But Kristen need not have been coerced. (48d) only says that John's choosing was coerced.

Let's compare cases where the nominal's argument is not a singular term. Suppose we deliberately treated John as a fool, and consider the nominal "our treatment of John." We have:

(49a) Our treatment of John was deliberate.

(49b) Our treatment of John was as a fool.

(49a) is plausibly predicational. Notice:

(50a) I considered our treatment of John deliberate.

(49b) on the other hand fails tests for being predicational:

(50b) \# I considered our treatment of John as a fool.

That can't felicitously be read in the intended way, to mean that I considered our treatment of John to be treatment as a fool. But neither is (49b) plausibly read as equative. "Our treatment of John" and "as a fool" don't seem to designate any single entity. So it's promising to regard (49b) as specificational. What the post-copular element is contributing here is an argument to what comes before the copula. (That's plausibly what's going on in $(46 \mathrm{a} / \mathrm{b})$, too, if we count Kristen as an argument to the predicate "(was) the woman John was seeing.")

I think that's essentially what's going on with examples like (5), as well:

(5) John's belief was that P.

In this case, too, the post-copular element is an argument to the nominalized verb that comes before the copula. Notice how easy it is to go from:

(51a) John's belief, which was that P, was formed hastily.

to:

(51b) John's belief that $\mathrm{P}$ was formed hastily. ${ }^{19}$

19 Higgins argues that (i) "John's claim is that you were lying" is specificational (see pp. 318ff). Iatridou and Varlokosta 1998 discuss claims whose precopular elements are free relatives, rather than nominals; for example: (ii) "What John claims is that you are lying." They tentatively argue that the relative clauses here are referential, and that examples like (ii) are equative rather than specificational. I grant that "what John claims" can sometimes be referential (e.g., "What John claims is preposterous"). But I doubt their diagnosis of (ii). Their strategy seems also to predict that this should be OK: (iii) "John had to choose between Kristen and his work. What he chose was Kristen, wasn't \#she?" But it's not. I think that (iii), and likewise (ii), may be specificational. My claim in the text, however, is only that sentences like (i) are specificational. 
If we go with Mikkelsen's analysis of the specificational copula, then the claim that (48c) and (5) are specificational means that they should be analyzed as follows:

(48c) John's choice was Kristen.

$\left(48 \mathrm{c}^{\prime}\right) \lambda x($ John chose $x)$ (Kristen)

(5) John's belief was that P.

(5') $\lambda \varphi($ John believed $\varphi)$ (that P)

This might solve the issues we had with Oscar's secret desire, too:

(33b) Oscar's secret desire is that he be well-liked.

$\left(33 b^{\prime}\right) \lambda \varphi$ (Oscar secretly desires $\varphi$ ) (that he be well-liked)

In both (5) and (33b), we should understand the that-clause to be supplying an argument to the cognitive nominal that precedes the copula.

\section{JOHN'S REASON}

The intuitive similarity between (5) and (7) suggests that something analogous is going on with (7):

(5) John's belief was that P.

(7) John's reason was that P.

That is, even if the orthodox semantic analysis of that-clauses is right, and "that P" is a singular term, the role it's playing in (7) is to specify John's reason, not to designate something that (7) equates with John's reason. Thus, (7) isn't offering us any direct insight into the ontology of reasons.

I'll close with a concession. With "reason," unlike "belief" and "desire" and "choice," we have only the nominal form to consider. As we observed in $\S 2$, there doesn't seem to be any way to express (7) using a verbal form of "reason." This makes it harder to think about what the argument structure of "reason" might be. Clearly it does accept arguments: we can talk about John's reason to resign or his reason to believe his secretary plans to expose him. But I can't easily reformulate (7) in any way that makes it clear that "that $\mathrm{P}$ " is another argument. So the doubts I'm raising about the linguistic argument against statism have to rest on the doubts about the allegedly analogous (5). Perhaps (5) and (7) really aren't so similar after all, and a case can be made that (7) is equative even though (5) is not. If so, that will also be philosophical progress. 


\section{BIBLIOGRAPHY}

Kent Bach, "Do belief reports report beliefs?" Pacific Philosophical Quarterly 79 (1997), $215-41$

John Broome, "Reasons," in Wallace, Smith, Scheffler, and Pettit, eds., Reason and Value (Oxford, 2004), 28-55

Jonathan Dancy, Practical Reality (Oxford, 2000)

David Dowty, "The dual analysis of adjuncts/complements in categorial grammar," in Lang, Maienborn, and Fabricius-Hansen, eds., Modifying Adjuncts (de Gruyter, 2003); http://www.ling.ohio-state.edu/ dowty/papers/degruyter.8x11.pdf

Joseph Emonds, "A reformulation of certain syntactic transformations," in Peters, ed., Goals of Linguistic Theory (Prentice-Hall, 1972), 21-63

Peter Geach, “On what there is,” Arist Society Suppl 25 (1951), 125-36

Gilbert Harman, "Category mistakes in M\&E," Philosophical Perspectives 17 (2003), $165-80$

Irene Heim and Angelika Kratzer, Semantics in Generative Grammar (Blackwell, 1998)

Caroline Heycock and Anthony Kroch, "Inversion and equation in copular sentences," in Alexiadou, Fuhrhop, Kleinhenz, and Law, eds., ZAS Papers in Linguistics 10 (1998), 71-87

Caroline Heycock and Anthony Kroch, "Pseudocleft connectedness: implications for the LF interface level," Linguistic Inquiry 30 (1999), 365-97

F. Roger Higgins, The Pseudo-Cleft Construction in English (MIT dissertation, 1973); http://hdl.handle.net/1721.1/12988

Rodney Huddleston and Geoffrey Pullum, The Cambridge Grammar of the English Language (Cambridge, 2002)

John Hyman, “How knowledge works," Phil Quarterly 49 (1999), 433-51

Sabine Iatridou and Spyridola Varlokosta, "Pseudoclefts crosslinguistically," Natural Language Semantics 6 (1998), 3-28

David Kaplan, "Demonstratives," in Almog, Perry and Wettstein, eds., Themes from Kaplan (Oxford, 1989), 481-563

Jeffrey King, "Designating propositions," Philosophical Review 111 (2002), 341-71 
Jan Koster, "Why subject sentences don't exist," in Keyser, ed., Recent Transformational Studies in European Linguistics (MIT Press, 1978), 53-64

Wolfgang Künne, Conceptions of Truth (Oxford, 2005)

John McDowell, Mind and World (Harvard, 1994)

John McDowell, "Knowledge and the internal," Philosophy and Phenomenological Research 55 (1995), 877-93; reprinted in Meaning, Knowledge and Reality (Harvard, 1998), 395-413

Michael McKinsey, “The semantics of belief ascription,” Nous 33 (1999), 519-57

Line Mikkelsen, Specifying Who (UC Santa Cruz dissertation, 2004); http://socrates.berkeley.edu/ mikkelse/dissertation.html

Marc Moffett, “Constructing attitudes,” Protosociology 21 (2005): 105-28; http://www.uwyo.edu/moffett/research/attitudes.pdf

Friederike Moltmann, "Propositional attitudes without propositions," Synthese 135 (2003a), 77-118

Friederike Moltmann, “Nominalizing quantifiers," J Phil Logic 32 (2003b), 445-81

Friederike Moltmann, "Nonreferential complements, nominalizations, and derived objects," J Semantics 21 (2004), 1-43

Andrea Moro, The Raising of Predicates (Cambridge, 1997)

Derek Parfit, “Reasons and motivation," in Arist Society Suppl 71 (1997), 99-130

Derek Parfit, "Normativity," in Shafer-Landau, ed., Oxford Studies in Metaethics, Volume 1 (Oxford, 2006)

Terence Parsons, “On denoting propositions and facts," Philosophical Perspectives 7 (1993), 441-60

Barbara Partee, "Ambiguous pseudoclefts with unambiguous be," in Berman, Choe, and McDonough, eds., Proceedings of NELS 16 (1986), 354-66; reprinted in Compositionality in Formal Semantics (Blackwell, 2004), 190-202

Barbara Partee, "Noun-phrase interpretation and type-shifting principles," in Groenendijk, de Jongh, and Stokhof, eds., Studies in Discourse Representation Theory and the Theory of Generalized Quantifiers (Foris, 1987), 115-93; reprinted in Compositionality in Formal Semantics (Blackwell, 2004), 203-30 
James Pryor, "There is immediate justification," in Steup and Sosa, eds., Contemporary Debates in Epistemology (Blackwell, 2005)

Agustin Rayo and Steve Yablo, "Nominalism through de-nominalization," Nous 35 (2001), 74-92

Maribel Romero, “Concealed questions and specificational subjects," Linguistics and Philosophy 28 (2005), 687-737

Tobias Rosefeldt, “"That'-clauses and non-nominal quantification," Phil Studies forthcoming; http://www.philosophie.unihd.de/rosefeldt/RosefeldtThatClauses.pdf

J.R. Ross, "Adjectives as noun phrases," in Reibel and Schane, eds. Modern Studies in English: Readings in Transformational Grammar (Prentice-Hall, 1969)

Susan Rothstein, "Small clauses and copula constructions," in Cardinaletti and Guasti, eds., Small Clauses (Academic Press, 1995), 27-48

Stephen Schiffer, The Things We Mean (Oxford, 2003)

Philippe Schlenker, "Clausal equations (a note on the connectivity problem)," Natural Language and Linguistic Theory 21 (2003), 157-214

Wilfrid Sellars, "Grammar and existence. A preface to ontology," in Science, Perception and Reality (Humanities Press, 1963)

Wilfrid Sellars, Naturalism and Ontology (Ridgeview, 1979)

Russ Shafer-Landau, Moral Realism: a Defence (Oxford, 2005)

Nico Silins, Reasons and Armchair Knowledge (Oxford dissertation, 2004)

Peter Unger, Ignorance (Oxford, 1975)

Zeno Vendler, Linguistics in Philosophy (Cornell, 1967)

C.J.F. Williams, What Is Existence? (Clarendon, 1981)

Edwin Williams, "Semantic versus syntactic categories," Linguistics and Philosophy 6 (1983), 423-46

Steve Yablo, "How in the world?" Phil Topics 24 (1996), 255-85 